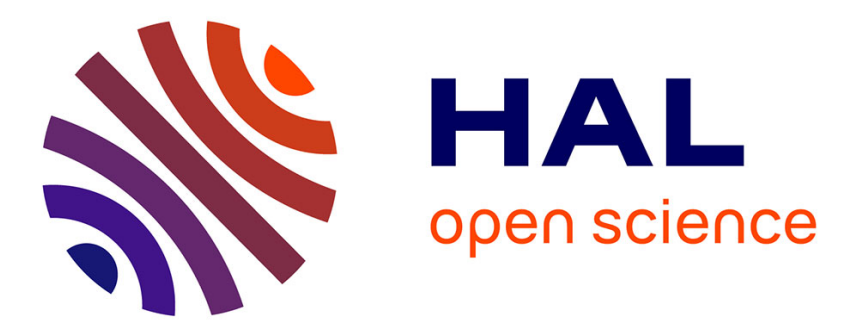

\title{
Relationships between human cortical bone toughness and collagen cross-links on paired anatomical locations
}

Rémy Gauthier, Hélène Follet, Max Langer, Evelyne Gineyts, Frédéric Rongieras, Françoise Peyrin, David Mitton

\section{- To cite this version:}

Rémy Gauthier, Hélène Follet, Max Langer, Evelyne Gineyts, Frédéric Rongieras, et al.. Relationships between human cortical bone toughness and collagen cross-links on paired anatomical locations. BONE, 2018, 112, pp.202-211. 10.1016/j.bone.2018.04.024 • hal-01807344

\section{HAL Id: hal-01807344 \\ https://hal.science/hal-01807344}

Submitted on 4 Jun 2018

HAL is a multi-disciplinary open access archive for the deposit and dissemination of scientific research documents, whether they are published or not. The documents may come from teaching and research institutions in France or abroad, or from public or private research centers.
L'archive ouverte pluridisciplinaire HAL, est destinée au dépôt et à la diffusion de documents scientifiques de niveau recherche, publiés ou non, émanant des établissements d'enseignement et de recherche français ou étrangers, des laboratoires publics ou privés. 


\title{
Relationships between human cortical bone toughness and collagen cross- links on paired anatomical locations
}

\author{
Rémy Gauthier ${ }^{1,3}$, Hélène Follet ${ }^{2}$, Max Langer ${ }^{3}$, Evelyne Gineyts ${ }^{2}$, Frédéric Rongiéras ${ }^{1,4}$, \\ Françoise Peyrin ${ }^{3}$ and David Mitton ${ }^{1, *}$ \\ 1 Univ Lyon, Université Claude Bernard Lyon 1, IFSTTAR, LBMC UMR_T9406, F69622, Lyon, France; \\ 2 Univ Lyon, Université Claude Bernard Lyon 1, INSERM, LYOS UMR1033, F69008, Lyon, France ; \\ 3 Univ Lyon, CNRS UMR 5220, Inserm U1206, INSA Lyon, Université Claude Bernard Lyon 1, Creatis, F69621 \\ Villeurbanne Cedex, France; \\ 4 Service Chirurgie Orthopédique et Traumatologie - Hôpital Desgenettes, 69003, Lyon, France; \\ * Corresponding author: david.mitton@ifsttar.fr
}

\begin{abstract}
Human cortical bone fracture processes depend on the internal porosity network down to the lacunar length scale. Recent results show that at the collagen scale, the maturation of collagen cross-links may have a negative influence on bone mechanical behavior. While the effect of pentosidine on human cortical bone toughness has been studied, the influence of mature and immature enzymatic cross-links has only been studied in relation to strength and work of fracture. Moreover, these relationships have not been studied on different paired anatomical locations. Thus, the aim of the current study was to assess the relationships between both enzymatic and non-enzymatic collagen cross-links and human cortical bone toughness, on four human paired anatomical locations. Single Edge Notched Bending toughness tests were performed for two loading conditions: a quasi-static standard condition, and a condition representative of a fall. These tests were done with 32 paired femoral diaphyses, femoral necks and radial diaphyses (18 women, age $81 \pm 12$ y.o.; 14 men, age $79 \pm$ 8 y.o.). Collagen enzymatic and non-enzymatic crosslinks were measured on the same bones. Maturation of collagen was defined as the ratio between immature and mature cross-links (CX). The results show that there was a significant correlation between collagen cross-link maturation and bone toughness when gathering femoral and radial diaphyses, but not when considering each anatomical location individually. These results show that the influence of collagen enzymatic and non-enzymatic cross-links is minor when considering human cortical bone crack propagation mechanisms.
\end{abstract}

Keyword: Human cortical bone, fracture toughness, strain rate, inter-sites, collagen cross-links 


\section{Introduction}

Bone fragility still remains difficult to understand as it is associated with several architectural, microstructural and even compositional parameters [1]. Among these, collagen fibers are of great importance in human cortical bone mechanical integrity [2-8]. Collagen represents more than $80 \%$ of the organic matter within bone tissue [7]. This organic material provides some ductility to bone whereas the mineral phase provides rigidity [4,7]. Changes in collagen with age are assumed to be involved in the decrease of bone mechanical properties with aging [9-11].

One of the most important mechanisms of collagen evolution is the formation of cross-links between collagen fibrils [12]. Two different cross-linking processes can be outlined. The first process is a stabilization of collagen fibers that is regulated by lysyl oxidase, which converts the amino groups of lysine and hydroxylysine to form allysine and hydroxyallysine. These molecules can then condensate with some residues of lysine or hydroxylysine to form immature derived divalent ketoimine crosslinks. By undergoing another reaction with lysine or hydroxylysine molecules, there is the formation of pyridinoline (PYD) and deoxypyridinoline (DPD) trivalent mature cross-links $[4,7,12,13]$. Their relative amounts can be expressed as the ratio between immature and mature cross-links, and are called the CX ratio in the current study (CX = [DHLNL + HLNL] / [PYD + DPD] [9].

A second mechanism involves a non-enzymatic reaction with glucose. This so-called glycation reaction is at the origin of the presence of Advanced Glycation End-products (AGEs) within bone tissue [4,12]. These non-enzymatic cross-links are thought to be involved in the decline of cortical mechanical properties with age $[11,14]$. Pentosidine (PEN), which is the most investigated AGE, can be accurately quantified in bone tissue using HPLC by natural fluorescence $[4,7,15]$.

While there are some studies investigating the relationships between collagen crosslinking and cortical bone mechanical properties $[4,7,9,11,14,16]$, there is little information on the relative difference between different anatomical locations [4]. In a previous study, our group showed that there was significant difference in bone fracture toughness of weight- and non-weight-bearing bones [17]. However, the compositional difference between a weight-bearing bone such as the femur, or a nonweight bearing bone, such as the radius, is not well known.

The influence of the CX ratio and PEN on cortical bone mechanical properties has been studied $[9,18$ 20]. PEN is associated with increased fragility of bone tissue in the elderly on weight-bearing bones such as the tibial or femoral shaft [21,22]. However, the effect of the CX ratio remains little studied. A recent study found that the CX ratio was associated with a decrease in post yield properties when comparing fibula extracted from children (10.14 \pm 4.56 y.o.) and adult donors (79.00 \pm 15.39 y.o.) [9]. To the authors' knowledge, there is no data on the influence of bone anatomical locations on these enzymatic and non-enzymatic cross-links and their effect on bone mechanical properties, specifically 
when comparing weight-bearing and non-weight-bearing bones. Moreover, the effect of the CX ratio on cortical bone behavior is not well known for a high-risk population with bone diseases and traumatisms.

The reason for this study is the lack of knowledge on bone fracture behaviour when considering paired weight-bearing and non-weight-bearing bones. While the influence of PEN on bone mechanical response is well known for weight-bearing bones, there is no data regarding the effect of the CX ratio for an adult population at risk regarding bone diseases.

Thus, the aim of this study is to quantify both enzymatic and non-enzymatic collagen cross-links on paired weight- and non-weight-bearing bones (femoral diaphysis (medial and lateral regions), femoral neck and radial diaphysis) in relation to toughness parameters for human cortical bone considering an adult population.

\section{Materials and Methods}

\subsection{Bone samples}

This study sampled from thirty-two human cadaver donors (18 women, age $81 \pm 12$ y.o.; 14 men, age $79 \pm 8$ y.o.). No additional information concerning eventual disease or medication history was available, except for hepatitis and Human Imunodeficiency Virus status. Whole femurs and radii were collected from these fresh cadaveric subjects (French Ministry of Education and Research, authorization $\left.\mathrm{n}^{\circ} \mathrm{DC}-2015-2357\right)$. Extracted bones were kept hydrated in saline soaked gauze and then stored at $-20{ }^{\circ} \mathrm{C}$ until sample preparation. Because of the non-availability of some of these bones, the final database was comprised of $2 \times 29$ femoral diaphysis (both from medial and lateral regions to directly evaluate the influence of anatomical region in the same location), 29 femoral inferior neck, which is the region where cortical thickness is suitable for sample preparation; and 31 radial anterior diaphysis specimens from the mid-diaphysis, which corresponds to the investigated region in a previous study aimed at investigating bone properties using guided waves that was performed on the same population [23].

\subsection{Biomechanical measurements}

The biomechanical experiments protocol used here are the same as in a previous study [17]. A summary of the methodology is summarized below.

\subsubsection{Sample preparation}

From each bone, from 20 to $25 \mathrm{~mm}$ long rectangular notched samples, with a width $\mathrm{W}=2.08 \pm$ $0.06 \mathrm{~mm}$ and a thickness $\mathrm{B}=1.01 \pm 0.02 \mathrm{~mm}$, were prepared so that their long side is parallel to the long axis of the diaphysis. The notch was machined in the transverse direction of the bone. As such, a 
crack will initiate and propagate perpendicularly to the osteons. In order to directly investigate the effect of strain rate, two samples were retrieved as closely as possible, so that we can assume that they are composed of the same material. The first was loaded under a quasi-static strain rate and the other at a representative fall rate. Thus, a total of 236 samples were prepared for this study. The samples were stored at $-20^{\circ} \mathrm{C}$ after preparation, then de-frosted the night before the mechanical tests and kept at $21^{\circ} \mathrm{C}$ in a physiological solution for $6 \mathrm{~h}$ before testing for rehydration.

\subsubsection{Biomechanical experiment}

Toughness experiments were performed using a three-point bending set up. For the quasi-static loading, which is the standard case, a strain rate of $10^{-4} \mathrm{~s}^{-1}$ was applied [24-26]. The fall-like loading condition was defined based on values found in the literature. Thus, the samples were loaded at a strain rate of nearly $10^{-1} \mathrm{~s}^{-1}$ [27] to emulate fall conditions. A load-displacement curve was recorded for each mechanical test and was used to obtain different parameters using the methods presented below.

\subsubsection{Fracture toughness measurement}

The non-linear J-integral introduced by Rice was measured to consider both elastic and plastic properties of human cortical bone [28]. The elastic strain energy release rate $\left(\mathrm{J}_{\mathrm{el}}\right.$ in $\left.\mathrm{kN} \cdot \mathrm{mm}^{-1}\right)$ and the plastic strain energy release rate $\left(J_{\mathrm{pl}}\right.$ in $\left.\mathrm{kN} \cdot \mathrm{mm}^{-1}\right)$ were calculated from toughness experiments. The formulae to calculate these mechanical parameters can be found in [17].

As cross-links may influence cortical bone capacity to undergo plastic deformation before breaking, we decided to divide the non-linear part of the load-displacement curve into two different areas associated to two different non-linear deformation mechanisms [9]. We assume that the non-linear part of the load displacement curve can be divided into two different fracture mechanisms that represent the development of a process zone and the actual propagation of a crack through the microstructure. Based on the shape of the curves obtained during the toughness experiment on human cortical bone, we choose to associate a strain energy parameter, $J_{\text {process }}\left(\mathrm{kN} \cdot \mathrm{mm}^{-1}\right)$, to the area between the yield load and the maximum load that would correspond to the development of a process zone due to rearrangement of the internal organization of cortical bone [29-31]. The second parameter, $\mathrm{J}_{\text {prop }}$ $\left(\mathrm{kN} . \mathrm{mm}^{-1}\right)$, is associated with the final part of the curve, from the maximum load until the complete failure, and would correspond to the actual formation of a main crack that would propagate through the cortical bone microstructure until failure. These two parameters can be assessed as follows (Figure $1)$ :

$$
\mathrm{J}_{\text {process }}=\frac{\eta \mathrm{A}_{\text {process }}}{\mathrm{B}(\mathrm{W}-\mathrm{a})}
$$


$\mathrm{J}_{\text {prop }}=\frac{\eta A_{\text {prop }}}{B(W-a)}$

where $\eta$ is a geometrical factor equal to 1.9 for Single Edge Notched Bending (SENB) specimen, B, W and a are the dimensions of the sample [32]. $A_{\text {process }}$ and $A_{\text {prop }}$ are the areas under the load displacement curve corresponding to $\mathrm{b}$ and $\mathrm{c}$ in Figure 1, respectively. We thus have the relationship between the different parameters:

$J_{p l}=J_{\text {process }}+J_{\text {prop }}$
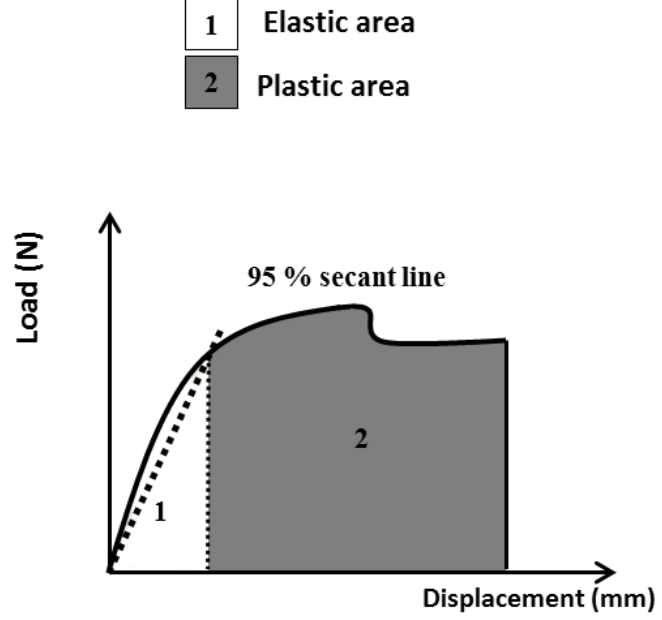
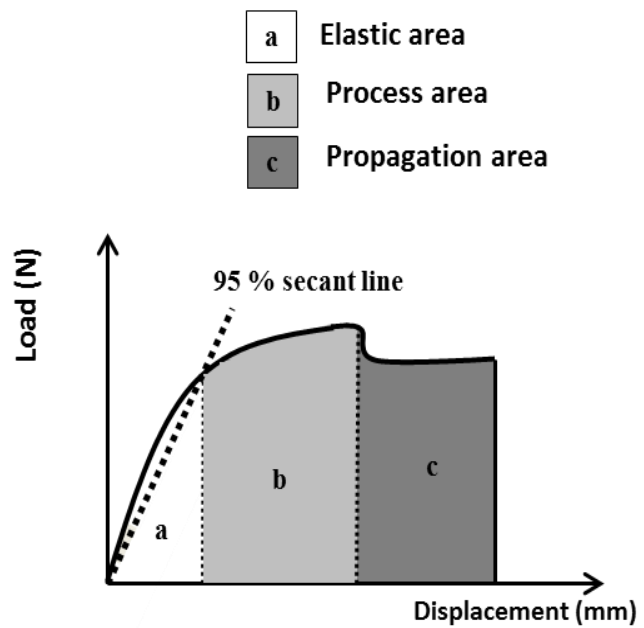

Figure 1 Typical load-displacement curve obtained with human cortical bone toughness experiments. On the left is the ASTM E-1820 suggestion of division [32]; on the right is the current study choice of division ( 2 column fitting figure).

\subsection{Biochemical measurements}

\subsubsection{Sample preparation}

The SENB samples used for biomechanical experiments were not used for biochemical measurements in order to keep them intact for further analysis using other modalities. In that way, cortical bone overages from the previously enounced sample preparation were kept frozen at $-20{ }^{\circ} \mathrm{C}$ for the biochemical measurements. This means that these measurements were done on a tissue closely surrounding the previously used region during the biomechanical experiments. The samples were cut into small pieces, powered in liquid nitrogen-cooled freezer mil (Spex Centriprep, Metuchen, USA), and demineralized with daily changing of $0.5 \mathrm{M}$ EDTA in $0.05 \mathrm{M}$ in Tris buffer, $\mathrm{pH} 7.4$ for $96 \mathrm{~h}$ at 4 ${ }^{\circ} \mathrm{C}$. The demineralized powder was then extensively washed with deionized water. The samples were then suspended in phosphate buffered saline $(0.15 \mathrm{M}$ sodium chloride, $0.1 \mathrm{M}$ sodium phosphate buffer, $\mathrm{pH}$ 7.4) and reduced in $\mathrm{NaBH}_{4}$ at room temperature for $2 \mathrm{~h}$ using a reagent/sample ratio of 1:30 (w/w). 
The reduced bone residues were washed, freeze-dried and hydrolyzed in $6 \mathrm{M}$ hydrochloric acid at 110 ${ }^{\circ} \mathrm{C}$ for $20 \mathrm{~h}$. These hydrolysates were used for the measurement of cortical bone cross-links and for the assessment of collagen and hydroxyproline. The availability of matter, the final database for biochemical measurements is composed of 2 × 29 femoral diaphysis (medial and lateral), 25 femoral necks and 30 radial diaphysis specimens.

\subsubsection{Cross-links measurements}

PYD and DPD mature cross-links and DHLNL and HLNL immature cross-links stabilized by NaBH4 reduction were extracted from the hydrolysates using a solid phase extraction column (Bond Elut Cellulose, Agilent Technologies, Santa Clara, CA, USA) to remove interfering molecules. The DHLNL, HLNL, PYD and DPD cross-links were then investigated using an Alliance 2695 separation HPLC system equipped with a Waters Micromass ${ }^{\circledR} \mathrm{ZQ}^{\mathrm{TM}}$ Single Quadrupole Mass Spectrometer, a 2647 Multi $\lambda$ fluorescence detector and Empower2 chromatography data software (Waters Corp. Milford, MA, USA). The species were separated on a C18 Atlantis ${ }^{\circledR} \mathrm{T} 3,3 \mu \mathrm{m}, 4.6 \times 100 \mathrm{~mm}$ reversedphase column protected by an Atlantis ${ }^{\circledR}$ T3, $3 \mu \mathrm{m}, 4.6 \times 20 \mathrm{~mm}$ guard cartridge (Waters Corp. Milford, MA, USA), maintained at $25{ }^{\circ} \mathrm{C}$, and using a gradient between an aqueous phase composed of $0.12 \%$ of heptafluorobutyric acid in $18 \mathrm{ohms}$ pure water and an acetonitrile organic phase at a flow rate of $1 \mathrm{ml} / \mathrm{min}$. Detection of the different molecules was performed by electrospray ionization mass spectrometry in a positive ion mode [33]. PYD and DPD calibrators were purchased from Quidel Corp. (San Diego, CA, USA). A PEN calibrator was kindly provided by Dr. M. Takahashi (Hamamatsu University School of Medicine, Shizuoka, Japan). DHLNL and HLNL standards were purified from foetal bovine cortical bone by HPLC and calibrated using the ninhydrin reference method and leucine equivalence [34].

The ratio CX $=[$ DHLNL + HLNL $] /[$ PYD + DPD $]$ was used to express the state of cross-links maturation, which assessed collagen matrix maturation [9].

PEN quantification was performed investigating its natural fluorescence at an emission of $385 \mathrm{~nm}$ for PEN and at an excitation of $334 \mathrm{~nm}[35]$.

The weight proportion of bone collagen in the sample was analyzed by measuring hydroxyproline using a HPLC assay (Bio-Rad, Munich, Germany) [33,35-39] (Figure 2).

Results are given in mmol by mol of collagen (mmol / mol collagen). The amount of collagen was measured by accurately weighing and hydrolysed by $\mathrm{HCl} 6 \mathrm{M}$ [34]. 
HPLC Mass Spectrometry

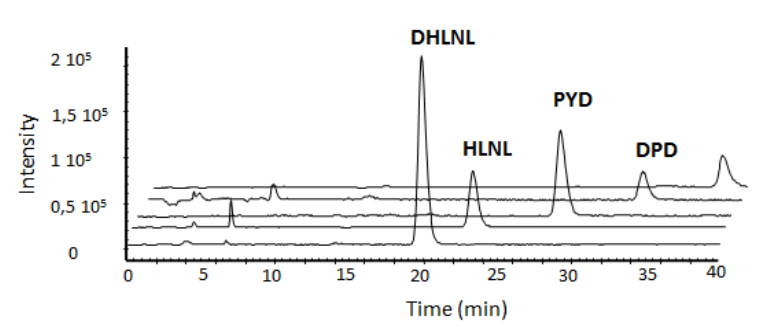

HPLC Fluorescence

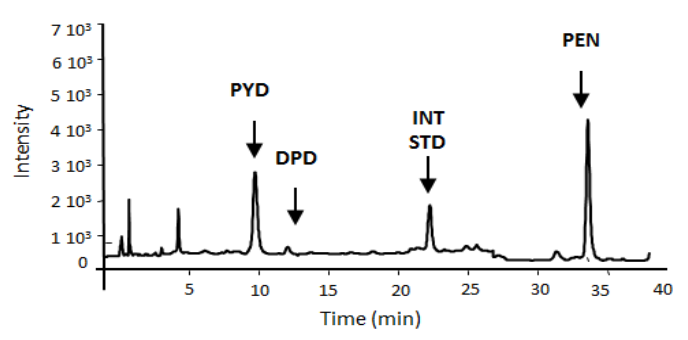

Figure 2 On the left is a typical chromatogram of DHLNL, HLNL, PYD and DPD of human cortical bone assessed with a mass spectrometry system. On the right is typical chromatogram of PYD, DPD and PEN of human cortical bone assessed with fluorescence system (2-column fitting figure).

\subsection{Statistical tests}

The normality of the distribution was assessed using Shapiro-Wilk's test. As normality was not obtained for all the parameters, results were analyzed using the Mann-Whitney test, and a nonparametric Wilcoxon test was applied for paired samples. Spearman's correlation tests determined the effect of age on biochemical parameters. These statistical tests were done using $R^{\odot}$ (The $R$ foundation for Statistical Computing, Austria) and Statview ${ }^{\circledR}$ (SAS Institute Inc., Campus Drive, Cary, NC 27513). As several statistical tests were applied, only results with a p-value $<0.01$ were considered as significant to take into account the multiple statistical tests and to strengthen the conclusions. 


\subsection{Results}

\subsection{Biomechanical experiments}

Mean values \pm Standard deviation (SD) for the four toughness parameters are presented in Figure 3 and in the Table 1 available in the supplementary materials section.

a

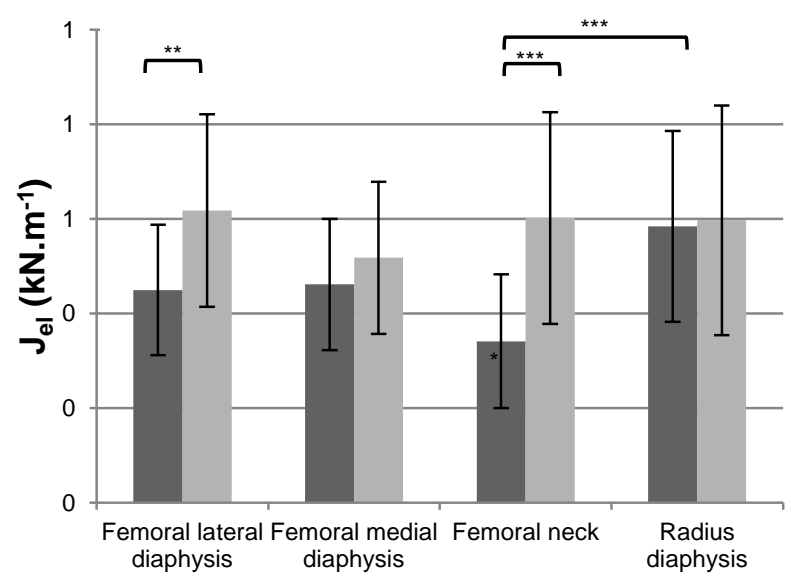

C

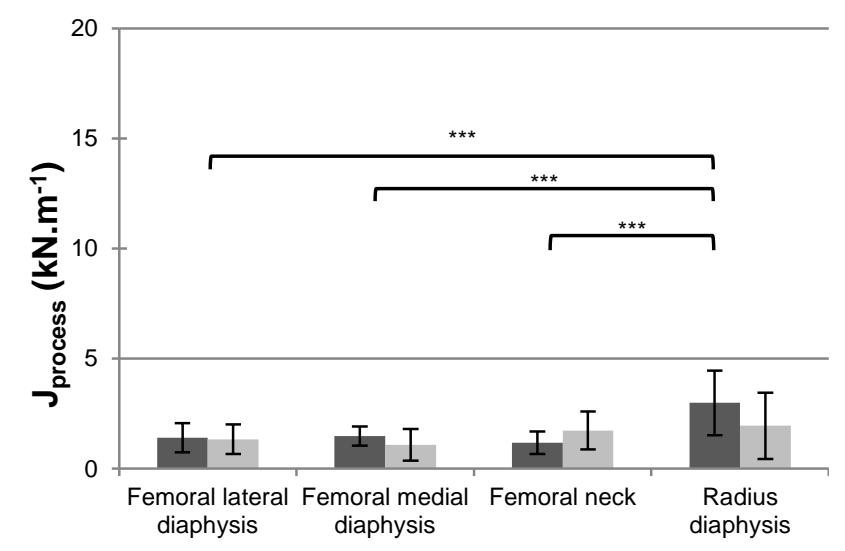

Quasi-static

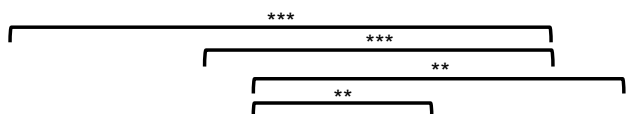

b

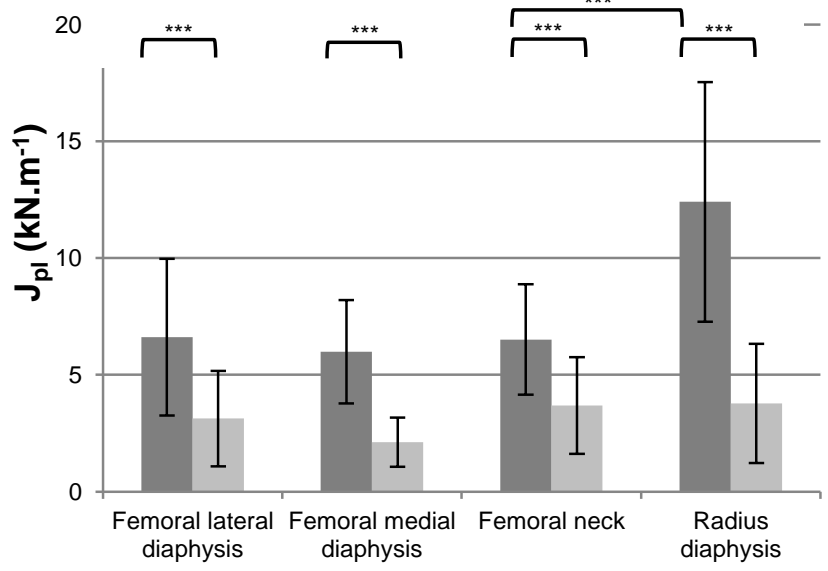

d

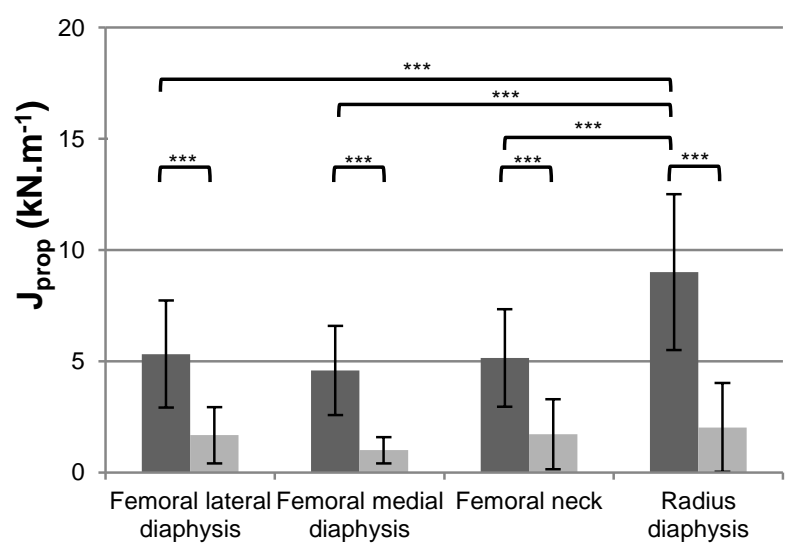

Figure 3 Bar charts values of a: $J_{\mathrm{el}} ; \mathrm{b}: \mathrm{J}_{\mathrm{pl}} ; \mathbf{c}$ : $\mathrm{J}_{\text {process }}$; and $\mathbf{d}$ : $\mathrm{J}_{\text {prop }}$ which are the strain energy release rates for the elastic, plastic, process zone development and propagation contribution, respectively, under quasi-static and fall-like loading condition. (Significant differences are indicated between groups $* * *$ p-value $<0.001$; $*$ p-value $<0.01$ ) (2-column fitting figure) 


\subsubsection{Linear elastic strain energy release rate}

Comparing quasi-static and fall conditions, a significant difference was observed only on the femoral lateral diaphysis and femoral neck: the elastic strain energy release rate increases when the rate is higher. The elastic strain energy release rate (Jel) increases about $27 \%$ for the lateral region of the diaphysis, and $43 \%$ for the femoral neck (see the supplementary materials).

Under a quasi-static loading rate, radius and the femoral lateral diaphysis present a significant higher elastic strain energy release rate than the femoral neck, with a maximum difference between the femoral neck and the radius $(-45 \%)$.

Under a fall loading rate, no difference was observed between anatomical locations (Figure 3).

\subsubsection{Non-linear elastic strain energy release rate}

Under fall-like conditions, there is a strain energy release rate $\left(\mathrm{J}_{\mathrm{pl}}\right)$ decrease for all sites. When distinguishing a process $\left(\mathrm{J}_{\text {process }}\right)$ and a propagation $\left(\mathrm{J}_{\text {prop }}\right)$ area on the load-displacement curve, we can observe a significant decrease of $\mathrm{J}_{\text {prop }}$ for the four locations, from $-199 \%$ for the femoral neck to -345 $\%$ for the radius; whereas there is no significant difference from the loading condition on $\mathrm{J}_{\text {process. }}$.

Under both under quasi-static and fall-like loading conditions, the overall non-linear deformation, represented by $\mathrm{J}_{\mathrm{pl}}$, appears to be higher than the elastic contribution $\mathrm{J}_{\mathrm{el}}$ (Figure 4). When defining different regimes within the plastic contribution, under a quasi-static condition, the propagation energy release rate, $\mathrm{J}_{\text {prop }}$, is higher than the elastic, $\mathrm{J}_{\mathrm{el}}$, and the process, $\mathrm{J}_{\text {process }}$, contribution. Meanwhile, under fall-like loading conditions, $\mathrm{J}_{\text {process }}$ and $\mathrm{J}_{\text {prop }}$ are comparable (Figure 4).

To summarize, the elastic contribution $\left(\mathrm{J}_{\mathrm{el}}\right)$ is significantly smaller than the plastic contribution $\left(\mathrm{J}_{\mathrm{pl}}=\right.$ $\mathrm{J}_{\text {process }}+\mathrm{J}_{\text {prop }}$ ) in the global mechanical response of cortical bone (Figure 4). For some cases (femoral lateral diaphyses and femoral neck) there is a significant increase of the elastic strain energy release rate $\left(\mathrm{J}_{\mathrm{el}}\right)$ with an increase of strain rate, and the main evolution is due to the significant decrease of $\mathrm{J}_{\mathrm{pl}}$ for all the anatomical locations. Within this plastic contribution $\left(\mathrm{J}_{\mathrm{pl}}\right)$ the main contributor is the propagation phase ( $\left.\mathrm{J}_{\text {prop }}\right)$ (Figure 4).

When comparing anatomical locations, the radius has a better capacity to resist crack propagation in the non-linear regime, considering both $\mathrm{J}_{\mathrm{pl}}$ and the distinct $\mathrm{J}_{\text {process }}$ and $\mathrm{J}_{\text {prop. }}$. These differences are not more significant under a fall-like loading condition. 


\section{Weight-bearing}
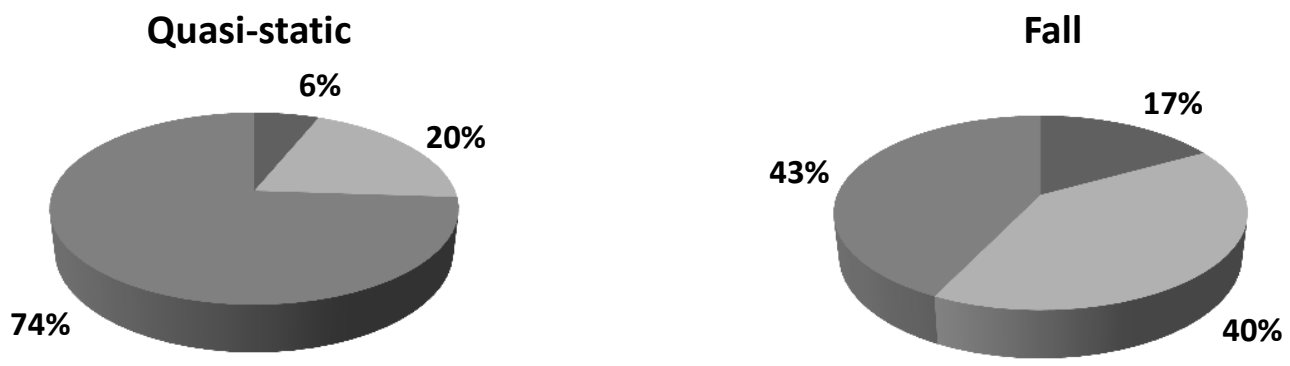

\section{Non-weight-bearing}
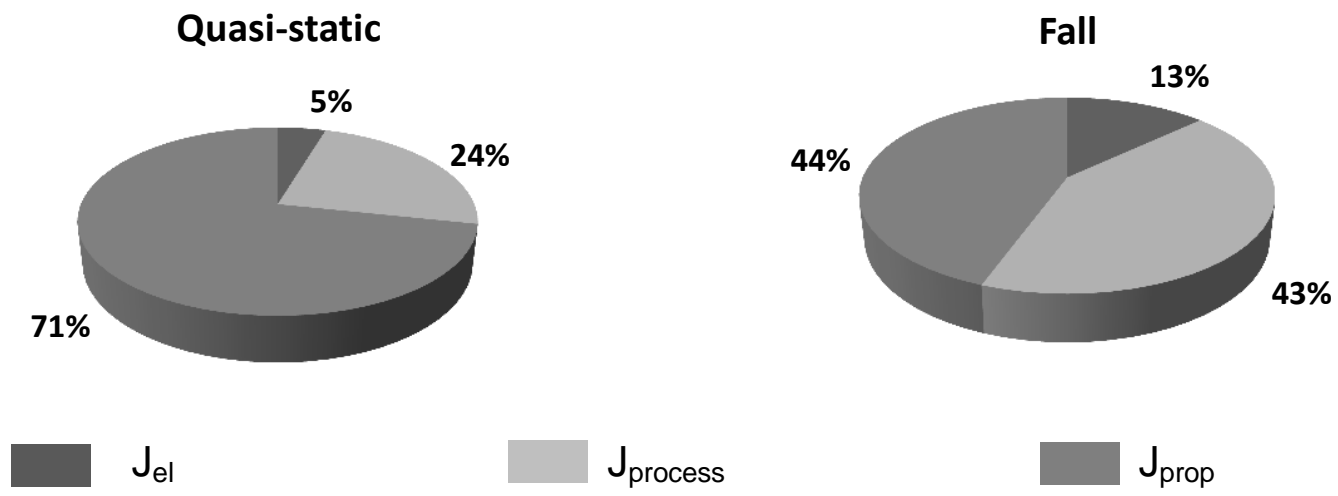

Figure 4 Relative contributions of the different mechanical parameters under quasi-static and fall-like loading conditions for weight-bearing and non-weight-bearing (2-column fitting figure).

\subsection{Biochemical measurements}

The mean values $( \pm \mathrm{SD})$ of enzymatic immature cross-links, enzymatic mature cross-links, CX ratio, Pen and collagen are reported in the Table 2 of the supplementary materials section.

Figure 5 shows the mean values obtained for the CX ratio and PEN measurements on the four anatomical locations. Significant differences were observed depending on the anatomical location. In particular, the CX ratio and PEN are significantly higher in the femoral neck than in femoral and radial diaphyses. The maximum relative difference is noted with the femoral medial diaphysis of about $44 \%$ for the CX ratio and $52 \%$ for PEN (p-value < 0.001). Radius also presents a significant higher CX ratio than femoral diaphysis with a higher difference of about $38 \%$ with the medial region (p-value < 0.0001) and a higher PEN content than in the medial region of the femoral diaphysis of $20 \%$. There is no difference between femoral lateral and medial diaphysis for CX ratio and PEN. 

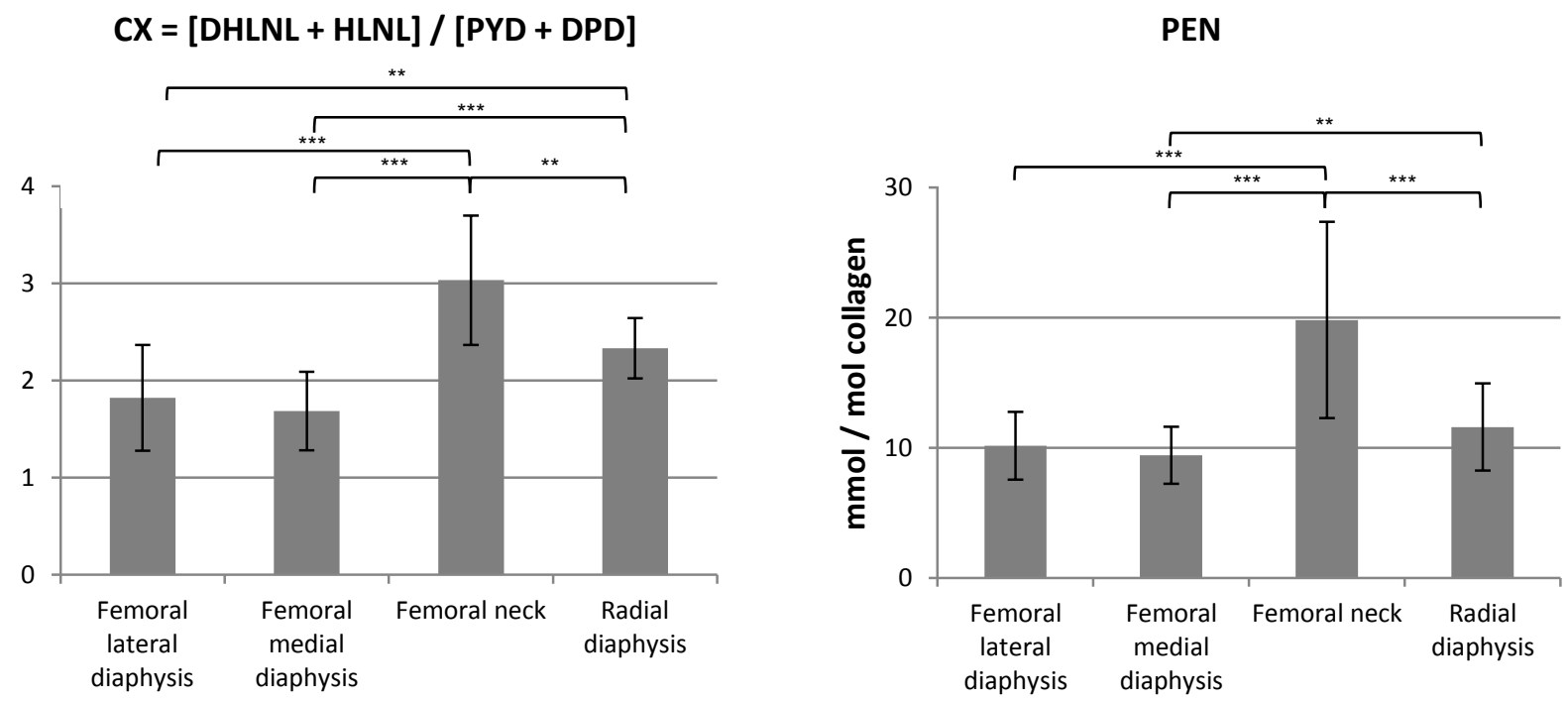

Figure 5 Bar charts mean values for CX ratio and PEN measurements for the four anatomical locations. (Significant differences are indicated $* * *$ p-value $<0.001$; ** p-value $<0.01)(2$-column fitting figure)

\subsection{Relationships between age, mechanical and biochemical properties}

For the four anatomical locations, PEN measurements were significantly positively correlated to the age of the donor whereas the CX ratio is negatively correlated to age only for the radius. Results from the correlation tests between age and PEN and CX ratio are given in Table 1.

Table 1 Spearman's coefficient between age and both CX ratio and PEN $\left(^{* *}\right.$ p-value $\leq 0.01,{ }^{* * * *} p$ value < 0.001, ns: non-significant). (1-column fitting table)

\begin{tabular}{lccc}
\hline \multicolumn{1}{c}{ Anatomical location } & $\mathbf{n}$ & CX & PEN \\
\hline Femoral lateral diaphysis & 29 & ns & $\mathbf{0 . 5 1}$ \\
Femoral medial diaphysis & 29 & ns & $\mathbf{0 . 5 5 ^ { * * * }}$ \\
Femoral neck & 25 & ns & $\mathbf{0 . 5 3}^{* *}$ \\
Radial diaphysis & 30 & $\mathbf{0 . 6 4}^{* *}$ & $\mathbf{0 . 6 7}^{* * * *}$ \\
\hline
\end{tabular}

No significant correlation was observed between the CX ratio and biomechanical parameters. A weak relation was found between the $\mathrm{CX}$ and $\mathrm{J}_{\text {process }}$ under a quasi-static loading condition on the medial femoral diaphysis and radius. This indicates a significant trend (Table 2). 
Table 2 Spearman's coefficient between $\mathrm{J}_{\text {process }}$ and $\mathrm{CX}$ ratio for the four anatomical locations and the quasi-static and fall loading conditions (all non-significant: $p>0.01$; ${ }^{*}$ Border line: $p<$ 0.05). (1-column fitting table)

\begin{tabular}{cccc}
\hline Anatomical location & $\mathbf{n}$ & \multicolumn{2}{c}{$\mathbf{J}_{\text {process }}-$ CX ratio } \\
\hline Femoral lateral diaphysis & 29 & Quasi-static & $\mathbf{0 . 2 5}$ \\
Femoral medial diaphysis & 29 & Fall & $-\mathbf{0 . 1 3}$ \\
& & Quasi-static & $\mathbf{0 . 5 3}$ \\
Femoral neck & 25 & Fall & $\mathbf{0 . 0 6}$ \\
Radial diaphysis & & Quasi-static & $\mathbf{0 . 0 4}$ \\
& 30 & Fall & $\mathbf{0 . 1 5}$ \\
& & Quasi-static & $\mathbf{0 . 5 2}$ \\
& & Fall & $\mathbf{- 0 . 0 8}$ \\
\hline
\end{tabular}

There was no significant correlation between $\mathrm{J}_{\text {prop }}$ and $\mathrm{CX}$ for the quasi-static condition on all the investigated anatomical locations. A marginal weak relation was observed for the lateral region of the femoral diaphysis under a fall-like loading condition (Table 3). No trend was observed here.

Table 3 Spearman's coefficient between Jprop and CX ratio for the four anatomical locations and the quasi-static and fall loading conditions (all non-significant: $p>0.01$; * Border line: $\mathbf{p}<$ 0.05). (1-column fitting table)

\begin{tabular}{cccc}
\hline Anatomical location & $\mathbf{n}$ & \multicolumn{2}{c}{$\mathbf{J}_{\text {prop }}-\mathbf{C X}$ ratio } \\
\hline Femoral lateral diaphysis & 29 & Quasi-static & $\mathbf{- 0 . 1 2}$ \\
& & Fall & $\mathbf{0 . 4 9}$ \\
Femoral medial diaphysis & 29 & Quasi-static & $\mathbf{0 . 2 8}$ \\
Femoral neck & 25 & Fall & $\mathbf{0 . 0 7}$ \\
& & Quasi-static & $\mathbf{0 . 2 6}$ \\
Radial diaphysis & 30 & Fall & $\mathbf{- 0 . 1 1}$ \\
& & Quasi-static & $\mathbf{0 . 2 8}$ \\
& & Fall & $\mathbf{0 . 3 6}$ \\
\hline
\end{tabular}

There was a significant correlation between the $\mathrm{CX}$ ratio and $\mathrm{J}_{\text {process }}$ when we investigated the gathered population of femoral and radial diaphyses. In a similar manner, this correlation was significant for $\mathrm{J}_{\text {prop }}$ (Figure 6). Regarding the large differences found concerning the biochemical results between the femoral neck and the other locations, this location was not considered in these correlation tests. These correlations were not significant if we included the femoral neck. 

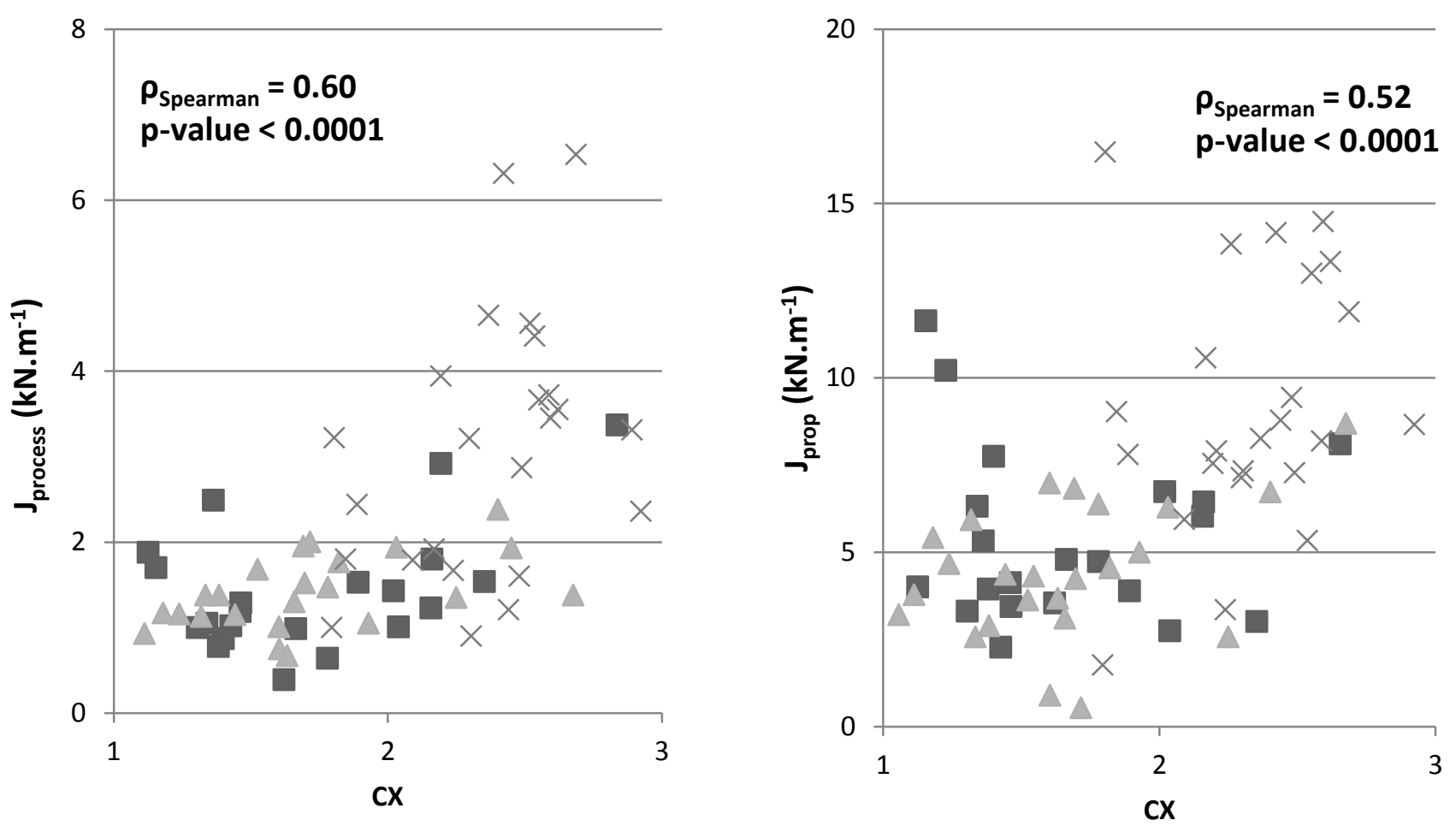

Femoral Lateral diaphysis $\triangle$ Femoral Medial diaphysis $\times$ Radial diaphysis

Figure 6. $\mathbf{J}_{\text {process }}$ (left) and $J_{\text {prop }}$ (right) under quasi-static loading condition in function of $\mathbf{C X}$.

Femoral and radial diaphyses are gathered in a same population for the correlation. Spearman coefficient and p-value are given (2- column fitting figure).

Figure 7 shows $\mathrm{J}_{\text {process }}$ and $\mathrm{J}_{\text {prop }}$ measured under fall-like loading condition in function of the $\mathrm{CX}$ ratio for the gathering population of femoral and radial diaphyses. We can observe here that if there is no correlation between $\mathrm{J}_{\text {process }}$ and CX, then we found a significant relation between $\mathrm{J}_{\text {prop }}$ and the ratio. This correlation is nevertheless weaker than under a quasi-static condition. 

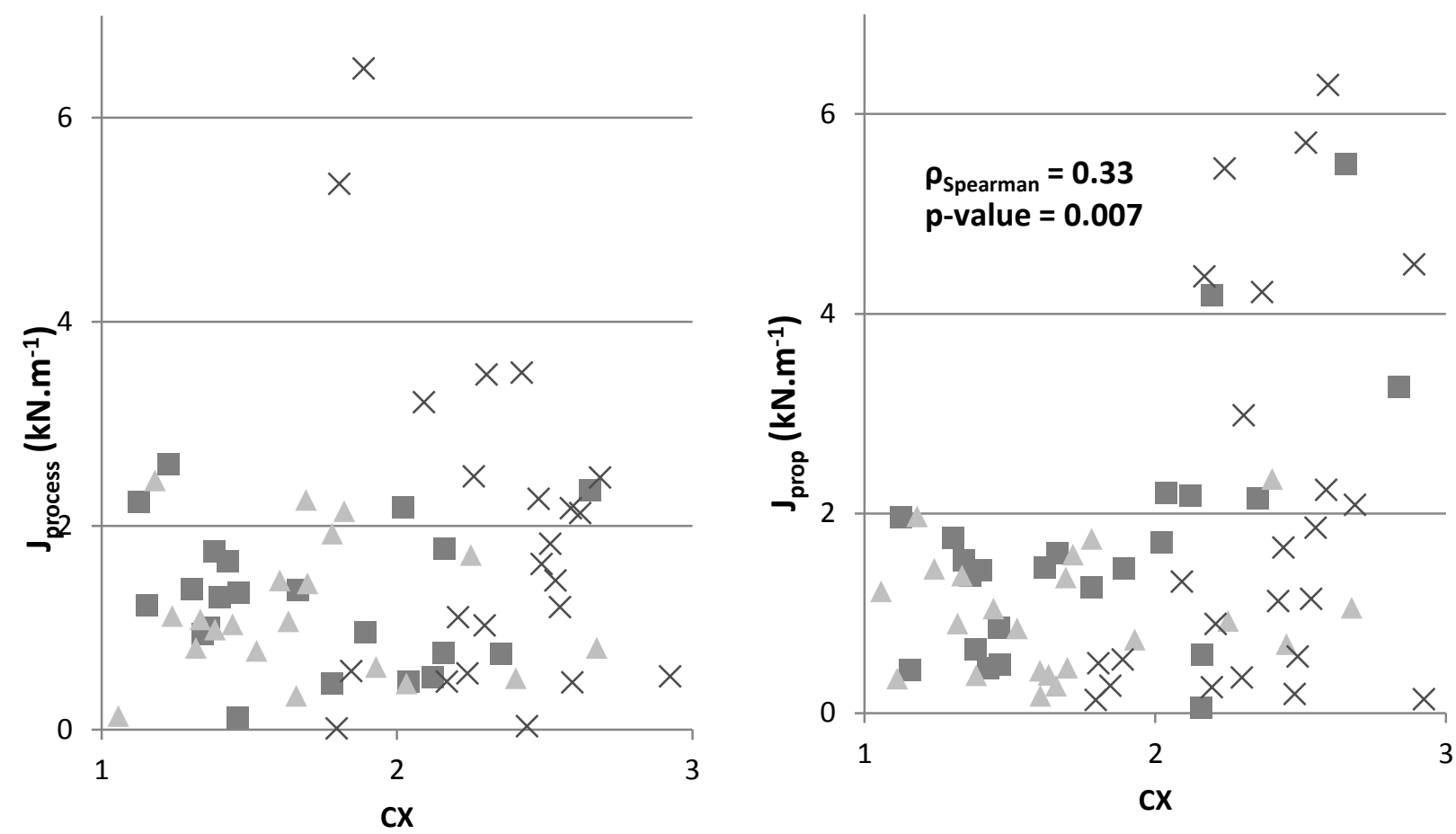

Femoral Lateral diaphysis $\triangle$ Femoral Medial diaphysis $\times$ Radial diaphysis

Figure 7. $\mathbf{J}_{\text {process }}$ (left) and $\mathbf{J}_{\text {prop }}$ (right) under fall-like loading condition in function of $\mathbf{C X}$.

Femoral and radial diaphyses are gathered in a same population for the correlation. Spearman coefficient and p-value are given when significant (2-column fitting figure).

No relation was found when considering PEN even by gathering the anatomical locations. 


\section{Discussion}

This study investigated the potential relationships between fracture behavior, both under quasi-static and fall-like loading conditions, and collagen maturation of human cortical bone considering four paired anatomical locations extracted from a population of 32 donors (18 women, age $81 \pm 12$ y.o.; 14 men, age $79 \pm 8$ y.o.).

\section{- Biomechanical measurement}

The results show that under a quasi-static loading condition, non-linear mechanisms are mainly due to a propagation mechanism. Under a fall-like loading rate, $\mathbf{J}_{\text {process }}$ and $\mathbf{J}_{\text {prop }}$ have the same order of magnitude, reflecting an equivalent contribution to the non-linear crack propagation mechanisms. The effect of strain rate on the propagation mechanism, $\mathrm{J}_{\text {prop}}$, is the same as previously observed for other parameters [17]: there is a lower value at higher a rate (Figure 3). For the process zone development mechanism, there is no influence from strain rate. The propagation contribution is the most affected by the increase of rate.

Dealing with differences in the biomechanical parameters between the four anatomical locations, the results are the same for $J_{\text {process }}$ and $J_{\text {prop }}$ as $J_{p l}$. Under a quasi-static condition, the radius presents a greater capacity to undergo non-linear mechanisms, both for the process zone development and for the propagation mechanisms. Under a fall-like condition, the femoral lateral diaphysis, femoral neck and radius present the same non-linear capacity to resist crack propagation (Figure 3).

These results show that the radius, which is a non-weight bearing bone, is more able to resist crack propagation in a quasi-static loading condition when considering the non-linear mechanisms. In a previous study, the authors compared the toughness of the radius and the tibia [17]. The results obtained were the same: the radius has a better capacity to resist crack propagation. The results found in the current study may also be due to the different analyzed regions used between the femur (medial and lateral) and the radius (anterior) as we know that these different regions are not subjected to the same mechanical environment [40]. In a previous study, Li et al. found significant differences between different regions of the same diaphysis [41]. Their results showed that the toughness measured on the medial part was significantly higher than the toughness measured on the anterior part (24\%). In the current study, the toughness measured on the medial part (femoral diaphysis, weight-bearing bone) was significantly lower $(50 \%)$ than that measured on the anterior part (radius, non-weight-bearing bone). This suggests a real influence from the weight- or non-weight-bearing nature of the investigated bones. 
- Biochemical measurement

The measured biochemical parameters in this study are in the range of results found in the literature $[4,9,15,36,37,42]$. While a significant correlation was found between CX and age only for the radius, PEN for each anatomical site correlated with age. This result is in accordance with the fact that PEN is a better biomarker for the ageing of the donor [7,43,44]. The increase in PEN content is associated with the accumulation of glucose and ribose within an organism due to some cell dysfunction due to ageing, whereas immature and mature cross-links concentration is assumed as constant in the elderly [4,37,45-47]. The values obtained on the femoral neck appear to be slightly different from the literature [15,42]. PEN content measured in the current study $(19.83 \pm 7.5 \mathrm{mmol} / \mathrm{mol}$ collagen $)$ is higher than in [15] (7.82 $\pm 3.45 \mathrm{mmol} / \mathrm{mol}$ collagen $)$ or in [42] ( $10 \mathrm{mmol} / \mathrm{mol}$ collagen $)$ measured on the cortical bone of the femoral neck. As a major part of cortical bone on the femoral neck was used to prepare samples for biomechanical experiments in the current study, the remaining part of the cortical bone was thin. Femoral neck is mainly composed of trabecular bone, despite all the experimental precautions it might be possible that this remaining part of the bone contained some region of the trabeculae. It has been shown in the past that the PEN content of trabecular bone is higher than in cortical bone $[4,42]$. Our group also found a significant difference in mature parameters (PYD + DPD) in cortical bone versus trabecular bone [48].

In the present study, we showed that enzymatic cross-link composition and PEN accumulation are highly dependent on the considered anatomical locations. Large significant differences were found between femoral diaphysis, femoral neck and radial diaphysis. The difference found between the lateral and medial part of the femur was relatively small, $8 \%$, suggesting that cross-link content is not dependent on the region of the femoral diaphysis (Figure 5).

The differences seen between the anatomical locations might be explained by different remodeling mechanisms. The amount of immature and mature cross-links are directly linked to the bone tissue turnover rate $[7,13]$. These differences can be due to the specific function of each bone in the skeleton, and in particular, whether it is a weight-bearing or a non-weight-bearing bone. As hypothesized in a previous study, physiological mechanical loading may stimulate collagen stabilization through the differentiation of immature cross-links to mature cross-links [4]. This is in accordance with results found in the current study: femoral diaphysis and femoral neck present a lower CX ratio, meaning that they are more mature than the radial diaphysis.

- Relationships between biomechanical and biochemical measurement

The relationships between biomechanical and biochemical properties found in the literature show that the maturation of collagen has an influence on cortical bone ability to undergo non-linear deformation 
[9]. In this previous study, the donors were from 5 to 99 years old and were separated into two groups ( 7 children of 10 y.o. in average, 3 adults of 79 y.o., in average). In the current study, performed on an adult population (50 - 95 y.o.), the decrease of CX ratio is not correlated to a decrease of $J_{\text {pl }}$, $J_{\text {process }}$ or $\mathrm{J}_{\text {prop }}$ under both a quasi-static and fall-like loading condition, when considering individual locations. By gathering femoral and radial diaphyses, we found that there was a significant correlation between $\mathrm{CX}$ ratio and $\mathrm{J}_{\text {process }}$ and $\mathrm{J}_{\text {prop }}$, thus suggesting that by investigating a larger population of donors, we may find significant correlations between collagen maturation and human cortical fracture behavior under a quasi-static loading condition. However, the correlation coefficients remain small ( $\rho=0.60$ and $\rho=0.52$ for $J_{\text {process }}$ and $J_{\text {prop }}$ respectively). Considering a fall-like loading condition, a significant correlation was only found with $J_{\text {prop }}$ with a smaller coefficient than under quasi-static condition $(\rho=$ $0.33)$.

The results found in the current study suggest that enzymatic cross-links have a minor influence on cortical bone toughness considering a population older than 50 y.o.. A similar result has already been stated using numerical simulation of mineral collagen fibrils [49]. In that study, they found that in the presence of enzymatic cross-links, deformation can occur through a sliding between collagen molecules, allowing a low load transfer between collagen and mineral platelets. These results also show that if a minor relation can be found under quasi-static loading, then this disappears under a strain rate representative of a fall. In their study, Zimmerman et al. found that at a higher loading rate, the slope of the fibril strain vs. tissue strain was higher [24]. Under a fall-like condition, the hypothesis of the stretching of the collagen fibrils is favored over interfibrillar sliding mechanisms.

Considering the effect of PEN on cortical bone mechanical behavior, the current study suggests that between 50 and 95 y.o., PEN is not correlated to any bone toughness variation. Findings in the literature state that an increase in PEN content is related to a decrease in bone mechanical properties $[11,16,19,50]$. In most of these studies, the effect of PEN was assessed by comparing a control population to a ribolysated one. A study by Nyman et al. evaluated the influence of PEN on a population from 49 to 90 y.o. and has shown a significant negative influence of PEN on bone fracture toughness (Pearson's coefficient $=-0.602$ ) [50]. However, another recent study performed on a population from 21 to 98 y.o. found results similar to the current ones, stating that PEN is only weakly correlated with both bone initiation fracture toughness and J-integral fracture toughness (Spearman's coefficient $=-0.34$ and -0.32 , respectively) [10]. Nyman et al. performed mechanical tensile testing on "dog bone" type specimens, whereas Granke et al. performed toughness testing on notched samples as in the current study. Standard tensile testing may be more sensitive to PEN than standard toughness experiments. A previous study performed on human femoral bone (from 19 to 89 y.o.) obtained a significant correlation between PEN and bone mechanical properties, including toughness measured following a standard method for toughness measurement [51]. Results showed that the correlation 
coefficient was higher between PEN and the work of fracture, which is obtained with tensile testing, than between PEN and elastic fracture toughness.

This study has some limitations. The limitations of biomechanical experiments, are discussed in [17]. The new parameters quantified in the current study do not modify these limitations.

Regarding biochemical measurements, the main limitation is that samples were taken from donors, and were then stored at $-20{ }^{\circ} \mathrm{C}$ until process them. Some studies have shown that the action of freezing may not affect the measured concentration with an HPLC system [52]. Considering that all the 236 samples tested in this study followed the same storage and preparation protocol, we can assume that a comparative analysis can be performed and that there is no inter-group bias.

Another limitation is that our studied population can be considered old (79 \pm 11 y.o.). It is well known that bone chemical composition changes with age. This point is important to consider when interpreting our results; studies on samples with a wider age distribution may lead to different results. Nonetheless, the samples used in the current study are representative of the patient demographic with the most bone fractures [53], and as such provides insight into factors that contribute to cortical bone toughness in this age group.

Finally, femoral neck has been shown to have slightly different properties than femoral or radial diaphysis. This can also be seen as a limitation in the current study. Samples prepared from the femoral neck may not be truly cortical samples, but more like a mix between cortical and trabecular. Nonetheless, femoral neck is one of the anatomical locations that is at greater risk for fracture in the elderly [54]. The region investigated in the current study is the most compact area on the femoral neck [55]. It is thus representative of reality. The femoral neck is a complex bone compared to other locations.

This study on human cortical bone found no correlation between collagen cross-link maturation and bone toughness for an adult population. Further work should be done to investigate the influence of other compositional parameters, such as osteopontin, on this particular sliding mechanism. Future investigations may be performed to evaluate the influence of some structural parameters on human cortical bone fracture behavior as it is know that some structural features, such as the osteons, play a major role in crack propagation mechanisms in human bone [59].

\section{Conclusion}

To the best of our knowledge, this is the first study dealing with the measurement of enzymatic and non-enzymatic cross-link content on almost 30 paired femoral diaphyses, femoral neck and radial diaphyses. It is also the first study comparing human cortical bone toughness and enzymatic cross-link content. In the current study, we showed that collagen maturation was dependent on anatomical 
location, and more specifically for weight- or non-weight-bearing bones. We also found that the relationship between collagen cross-link maturation and cortical bone toughness is not significant. A weak correlation was obtained between the CX ratio and cortical bone capacity to develop a process zone, implying the need of a better understanding of the different mechanisms involved in this particular mechanical regime. This process zone development is assumed to be associated with the emergence of micro-damage within the tissue.

\section{Conflict of interests}

The authors declare no conflict of interest. The founding sponsors had no role in the design of the study; in the collection, analyses, or interpretation of data; in the writing of the manuscript, and in the decision to publish the results.

\section{Acknowledgments}

The authors wish to thank Leila Ben Boubaker for her technical support. This work was done in the framework of LabEx PRIMES (ANR-11-LABX-0063). This study was partly funded by the Région Rhône-Alpes and by the ANR project MULTIPS (ANR-13-BS09-0006). The authors also want to thank the Fédération INGE'LYSE for its financial support.

\section{Bibliography}

[1] E. Seeman, P.D. Delmas, Bone quality--the material and structural basis of bone strength and fragility., N. Engl. J. Med. 354 (2006) 2250-2261. doi:10.1056/NEJMra053077.

[2] H. Oxlund, M. Barckman, G. Ørtoft, T.T. Andreassen, Reduced concentrations of collagen cross-links are associated with reduced strength of bone, Bone. 17 (1995) 365-371. doi:10.1016/8756-3282(95)00328-B.

[3] W. Wang, A. Elbanna, Crack propagation in bone on the scale of mineralized collagen fibrils: Role of polymers with sacrificial bonds and hidden length, Bone. 68 (2014) 20-31. doi:10.1016/j.bone.2014.07.035.

[4] M. Saito, K. Marumo, Collagen cross-links as a determinant of bone quality: A possible explanation for bone fragility in aging, osteoporosis, and diabetes mellitus, Osteoporos. Int. 21 (2010) 195-214. doi:10.1007/s00198-009-1066-z.

[5] H.S. Gupta, S. Krauss, M. Kerschnitzki, A. Karunaratne, J.W.C. Dunlop, a. H. Barber, et al., Intrafibrillar plasticity through mineral/collagen sliding is the dominant mechanism for the extreme toughness of antler bone, J. Mech. Behav. Biomed. Mater. 28 (2013) 366-382. doi:10.1016/j.jmbbm.2013.03.020.

[6] P. Zioupos, J.D. Currey, a. J. Hamer, The role of collagen in the declining mechanical properties of aging human cortical bone, J. Biomed. Mater. Res. 45 (1999) 108-116. doi:10.1002/(SICI)1097-4636(199905)45:2<108::AID-JBM5>3.0.CO;2-A. 
[7] S. Viguet-Carrin, P. Garnero, P.D. Delmas, The role of collagen in bone strength, Osteoporos. Int. 17 (2006) 319-336. doi:10.1007/s00198-005-2035-9.

[8] P. Zioupos, A.J. Hamer, J.D. Currey, The role of collagen in the declining mechanical properties of aging human cortical bone, 44th Annu. Meet. Orthop. Res. Soc. (1999) 108-116. doi:10.1002/(SICI)1097-4636(199905)45.

[9] J.-P. Berteau, E. Gineyts, M. Pithioux, C. Baron, G. Boivin, P. Lasaygues, et al., Ratio between mature and immature enzymatic cross-links correlates with post-yield cortical bone behavior: An insight into greenstick fractures of the child fibula, Bone. 79 (2015) 190-195. doi:10.1016/j.bone.2015.05.045.

[10] M. Granke, A.J. Makowski, S. Uppuganti, M.D. Does, J.S. Nyman, Identifying novel clinical surrogates to assess human bone fracture toughness, J. Bone Miner. Res. (2015) n/a-n/a. doi:10.1002/jbmr.2452.

[11] D. Vashishth, G.J. Gibson, J.I. Khoury, M.B. Schaffler, J. Kimura, D.P. Fyhrie, Influence of nonenzymatic glycation on biomechanical properties of cortical bone, Bone. 28 (2001) 195201. doi:10.1016/S8756-3282(00)00434-8.

[12] A.J. Bailey, Molecular mechanisms of ageing in connective tissues, Mech. Ageing Dev. 122 (2001) 735-755. doi:10.1016/S0047-6374(01)00225-1.

[13] A.J. Bailey, R.G. Paul, L. Knott, Mechanisms of maturation and ageing of collagen, Mech. Ageing Dev. 106 (1998) 1-56. doi:10.1016/S0047-6374(98)00119-5.

[14] E.A. Zimmermann, E. Schaible, H. Bale, H.D. Barth, S.Y. Tang, P. Reichert, et al., Age-related changes in the plasticity and toughness of human cortical bone at multiple length scales, Proc. Natl. Acad. Sci. 109 (2012) 11890-11890. doi:10.1073/pnas.1209596109.

[15] M. Saito, K. Fujii, S. Soshi, T. Tanaka, Reductions in degree of mineralization and enzymatic collagen cross-links and increases in glycation-induced pentosidine in the femoral neck cortex in cases of femoral neck fracture, Osteoporos. Int. 17 (2006) 986-995. doi:10.1007/s00198006-0087-0.

[16] A. a Poundarik, P.-C. Wu, Z. Evis, G.E. Sroga, A. Ural, M. Rubin, et al., A direct role of collagen glycation in bone fracture, J. Mech. Behav. Biomed. Mater. 50 (2015) 82-92. doi:10.1016/j.jmbbm.2015.05.025.

[17] R. Gauthier, H. Follet, M. Langer, S. Meille, J. Chevalier, F. Rongiéras, et al., Strain rate influence on human cortical bone toughness: A comparative study of four paired anatomical sites, J. Mech. Behav. Biomed. Mater. 71 (2017) 223-230. doi:10.1016/j.jmbbm.2017.03.015.

[18] B. Depalle, Z. Qin, S.J. Shefelbine, M.J. Buehler, Influence of cross-link structure, density and mechanical properties in the mesoscale deformation mechanisms of collagen fibrils, J. Mech. Behav. Biomed. Mater. 52 (2015) 1-13. doi:10.1016/j.jmbbm.2014.07.008.

[19] T.L. Willett, S. Sutty, A. Gaspar, N. Avery, M. Grynpas, In vitro non-enzymatic ribation reduces post-yield strain accommodation in cortical bone, Bone. 52 (2013) 611-622. doi:10.1016/j.bone.2012.11.014.

[20] S.Y. Tang, M.R. Allen, R. Phipps, D.B. Burr, D. Vashishth, Changes in non-enzymatic glycation and its association with altered mechanical properties following 1-year treatment with risedronate or alendronate, Osteoporos. Int. 20 (2009) 887-894. doi:10.1007/s00198-0080754-4.

[21] S.Y. Tang, U. Zeenath, D. Vashishth, Effects of non-enzymatic glycation on cancellous bone fragility, Bone. 40 (2007) 1144-1151. doi:10.1016/j.bone.2006.12.056. 
[22] S.Y. Tang, D. Vashishth, The relative contributions of non-enzymatic glycation and cortical porosity on the fracture toughness of aging bone, J. Biomech. 44 (2011) 330-336. doi:10.1016/j.jbiomech.2010.10.016.

[23] Q. Vallet, N. Bochud, C. Chappard, P. Laugier, J.-G. Minonzio, In Vivo Characterization of Cortical Bone Using Guided Waves Measured by Axial Transmission, IEEE Trans. Ultrason. Ferroelectr. Freq. Control. 63 (2016) 1361-1371. doi:10.1109/TUFFC.2016.2587079.

[24] E.A. Zimmermann, B. Gludovatz, E. Schaible, B. Busse, R.O. Ritchie, Fracture resistance of human cortical bone across multiple length-scales at physiological strain rates, Biomaterials. 35 (2014) 5472-5481. doi:10.1016/j.biomaterials.2014.03.066.

[25] Y.N. Yeni, D.P. Fyhrie, Fatigue damage-fracture mechanics interaction in cortical bone, Bone. 30 (2002) 509-514. doi:10.1016/S8756-3282(01)00696-2.

[26] M. a Kasapi, J.M. Gosline, Strain-rate-dependent mechanical properties of the equine hoof wall., J. Exp. Biol. 199 (1996) 1133-1146.

[27] Z. Foldhazy, Exercise-induced strain and strain rate in the distal radius, J. Bone Jt. Surg. - Br. Vol. 87-B (2005) 261-266. doi:10.1302/0301-620X.87B2.14857.

[28] J.R. Rice, A Path Independent Integral and the Approximate Analysis of Strain Concentration by Notches and Cracks, J. Appl. Mech. 35 (1968) 379. doi:10.1115/1.3601206.

[29] D. Vashishth, J.C. Behiri, W. Bonfield, Crack growth resistance in cortical bone: Concept of microcrack toughening, J. Biomech. 30 (1997) 763-769. doi:10.1016/S0021-9290(97)00029-8.

[30] Q.D. Yang, B.N. Cox, R.K. Nalla, R.O. Ritchie, Fracture length scales in human cortical bone: The necessity of nonlinear fracture models, Biomaterials. 27 (2006) 2095-2113. doi:10.1016/j.biomaterials.2005.09.040.

[31] T. Willett, D. Josey, R. Xing, Z. Lu, G. Minhas, J. Montesano, The micro-damage process zone during transverse cortical bone fracture : No ears at crack growth initiation, J. Mech. Behav. Biomed. Mater. 74 (2017) 371-382. doi:10.1016/j.jmbbm.2017.06.029.

[32] The American Society of Mechanical Engineers (ASME), E 1820-01: Standard Test Method for Measurement of Fracture Toughness, ... . Philadelphia PA Am. Soc. Test. .... (2006) 46. http://scholar.google.com/scholar?hl=en\&btnG=Search\&q=intitle:Standard+Test+Method+for + Measurement+of+Fracture+Toughness\#0.

[33] E. Gineyts, O. Borel, R. Chapurlat, P. Garnero, Quantification of immature and mature collagen crosslinks by liquid chromatography-electrospray ionization mass spectrometry in connective tissues, J. Chromatogr. B Anal. Technol. Biomed. Life Sci. 878 (2010) 1449-1454. doi:10.1016/j.jchromb.2010.03.039.

[34] E. Gineyts, F. Munoz, C. Bertholon, E. Sornay-Rendu, R. Chapurlat, Urinary levels of pentosidine and the risk of fracture in postmenopausal women: The OFELY study, Osteoporos. Int. 21 (2010) 243-250. doi:10.1007/s00198-009-0939-5.

[35] S. Viguet-Carrin, E. Gineyts, C. Bertholon, P.D. Delmas, Simple and sensitive method for quantification of fluorescent enzymatic mature and senescent crosslinks of collagen in bone hydrolysate using single-column high performance liquid chromatography, J. Chromatogr. B. 877 (2009) 1-7. doi:10.1016/j.jchromb.2008.10.043.

[36] H. Follet, S. Viguet-Carrin, B. Burt-Pichat, B. Dépalle, Y. Bala, E. Gineyts, et al., Effects of preexisting microdamage, collagen cross-links, degree of mineralization, age, and architecture on compressive mechanical properties of elderly human vertebral trabecular bone, J. Orthop. Res. 29 (2011) 481-488. doi:10.1002/jor.21275. 
[37] M. Saito, K. Marumo, K. Fujii, N. Ishioka, Single-Column High-Performance Liquid Chromatographic-Fluorescence Detection of Immature, Mature, and Senescent Cross-Links of Collagen, Anal. Biochem. 253 (1997) 26-32. doi:10.1006/abio.1997.2350.

[38] D.R. Eyre, T.J. Koob, K.P. Van Ness, Quantitation of hydroxypyridinium crosslinks in collagen by high-performance liquid chromatography, Anal. Biochem. 137 (1984) 380-388. doi:10.1016/0003-2697(84)90101-5.

[39] D.A. Pratt, Y. Daniloff, A. Duncan, S.P. Robins, Automated analysis of the pyridinium crosslinks of collagen in tissue and urine using solid-phase extraction and reversed-phase highperformance liquid chromatography, Anal. Biochem. 207 (1992) 168-175. doi:10.1016/00032697(92)90519-D.

[40] S. Judex, R.F. Zernicke, High-impact exercise and growing bone: relation between high strain rates and enhanced bone formation., J. Appl. Physiol. 88 (2000) 2183-2191.

[41] S. Li, A. Abdel-Wahab, V. V. Silberschmidt, Analysis of fracture processes in cortical bone tissue, Eng. Fract. Mech. 110 (2013) 448-458. doi:10.1016/j.engfracmech.2012.11.020.

[42] L. Karim, S.Y. Tang, G.E. Sroga, D. Vashishth, Differences in non-enzymatic glycation and collagen cross-links between human cortical and cancellous bone, Osteoporos. Int. 24 (2013) 2441-2447. doi:10.1007/s00198-013-2319-4.

[43] D.R. Eyre, M.A. Weis, J.J. Wu, Maturation of collagen ketoimine cross-links by an alternative mechanism to pyridinoline formation in cartilage, J. Biol. Chem. 285 (2010) 16675-16682. doi:10.1074/jbc.M110.111534.

[44] G.E. Sroga, A. Siddula, D. Vashishth, Glycation of human cortical and cancellous bone captures differences in the formation of maillard reaction products between glucose and ribose, PLoS One. 10 (2015) 1-19. doi:10.1371/journal.pone.0117240.

[45] R.W. Stout, Glucose tolerance and ageing, J. R. Soc. Med. 87 (1994) 608-9. http://www.pubmedcentral.nih.gov/articlerender.fcgi?artid=1294853\&tool=pmcentrez\&rendert ype=abstract\%5Cnhttp://www.ncbi.nlm.nih.gov/pubmed/7966111\%5Cnhttp://www.pubmedce ntral.nih.gov/articlerender.fcgi?artid=PMC1294853.

[46] A. Cerami, H. Vlassara, M. Brownlee, Glucose and Aging, Sci. Am. 256 (1987) 90-96. doi:10.1038/scientificamerican0587-90.

[47] D.R. Sell, V.M. Monnir, Structure elucidation of a senescence cross-link from human extracellular matrix. Implication of pentoses in the aging process, J. Biol. Chem. 264 (1989) 21597-21602.

[48] E. Gineyts, N. Portero-Muzy, H. Blain, P. Chavassieux, Contribution of Enzymatic and NonEnzymatic Collagen Crosslinks to Femoral Neck Fragility. Comparison Between Osteoporosis and Osteoarthritis, J Bone Min. Res. 26 (2011).

https://www.asbmr.org/Meetings/AnnualMeeting/AbstractDetail.aspx?aid=b92e43dc-3a4946f3-a8f1-dbe7caa3e8ee.

[49] T. Siegmund, M.R. Allen, D.B. Burr, Failure of mineralized collagen fibrils: Modeling the role of collagen cross-linking, J. Biomech. 41 (2008) 1427-1435. doi:10.1016/j.jbiomech.2008.02.017.

[50] J.S. Nyman, A. Roy, J.H. Tyler, R.L. Acuna, H.J. Gayle, X. Wang, Age-related factors affecting the postyield energy dissipation of human cortical bone, J. Orthop. Res. 25 (2007) 646-655. doi:10.1002/jor.20337.

[51] X. Wang, X. Shen, X. Li, C. Mauli Agrawal, Age-related changes in the collagen network and 
toughness of bone, Bone. 31 (2002) 1-7. doi:10.1016/S8756-3282(01)00697-4.

[52] K. Bergmann, G. Sypniewska, The influence of sample freezing at $-80^{\circ} \mathrm{C}$ for $2-12$ weeks on glycated haemoglobin (HbA1c) concentration assayed by HPLC method on Bio-Rad D-10@ auto-analyzer, Biochem. Medica. 421 (2016) 346-352. doi:10.11613/BM.2016.038.

[53] M.S. Nanes, C.B. Kallen, Osteoporosis, Semin. Nucl. Med. 44 (2014) 439-450. doi:10.1053/j.semnuclmed.2014.06.006.

[54] C.M. Court-Brown, B. Caesar, Epidemiology of adult fractures: A review, Injury. 37 (2006) 691-697. doi:10.1016/j.injury.2006.04.130.

[55] N. Loveridge, J. Power, J. Reeve, A. Boyde, Bone mineralization density and femoral neck fragility, Bone. 35 (2004) 929-941. doi:10.1016/j.bone.2004.05.025.

[56] B. Zappone, P.J. Thurner, J. Adams, G.E. Fantner, P.K. Hansma, Effect of Ca2+ ions on the adhesion and mechanical properties of adsorbed layers of human osteopontin., Biophys. J. 95 (2008) 2939-2950. doi:10.1529/biophysj.108.135889.

[57] P.K. Hansma, G.E. Fantner, J.H. Kindt, P.J. Thurner, G. Schitter, P.J. Turner, et al., Sacrificial bonds in the interfibrillar matrix of bone, J. Musculoskelet. Neuronal Interact. 5 (2005) 313315.

[58] P.J. Thurner, C.G. Chen, S. Ionova-Martin, L. Sun, A. Harman, A. Porter, et al., Osteopontin deficiency increases bone fragility but preserves bone mass, Bone. 46 (2010) 1564-1573. doi:10.1016/j.bone.2010.02.014.

[59] D.B. Burr, M.B. Schaffler, R.G. Frederickson, Composition of the cement line and its possible mechanical role as a local interface in human compact bone., J. Biomech. 21 (1988) 939-945. doi:10.1016/0021-9290(88)90132-7. 